\title{
ASPECTOS DA ANÁLISE, PROJETO E IMPLEMENTAÇÃO DE SISTEMAS DE INFORMAÇÃO EXPLORATÓRIA GEORREFERËNCIA
} ANTÔNIO CARLOS MATTANA*

\author{
DISSERTAÇÃO DE MESTRADO - Programa de Pós-Graduação em Geologia - UFPR \\ DATADE DEFESA: 9 nov. 2000
}

São abordados nesta dissertação elementos de organização, documentação e tratamento de informação exploratória georreferenciada, destacando pontos de modelagem conceitual e lógico-relacional topológica de um ambiente de suporte à decisão exploratória localizado, funcionalmente, na delimitação de áreas mais favoráveis para prospecção mineral em escala de detalhe e semidetalhe. É tomada, como estudo de caso em análise, a avaliação da favorabilidade de terrenos proterozóicos da região do Vale do Ribeira (PR-SP) para depósitos exalativos-sedimentares de Chumbo-Zinco, a partir da integração entre um modelo de depósito e um banco de feições geológicas deste tipo de depósito mapeadas em escala 1:100.000 e diagnósticas dos seus processos geradores. Os resultados estão apresentados também na forma de uma aplicação computacional, desenvolvida para ambiente Windows capaz de exibir dados selecionados segundo critérios de consulta estruturada e também um mapa da favorabilidade exploratória daquela região para aquele tipo de depósito mineral. A dissertação tem um enfoque metodológico, procurando agregar ao repertório geológico elementos da análise orientada a objetos, o que muito pode contribuir para problemas geológicos sejam não apenas implementáveis computacionalmente, mas também mais claramente colocados.

\footnotetext{
*E-mail: mattana@geologia.ufpr.br
} 